\title{
In vitro assessment of adsorbents aiming to prevent deoxynivalenol and zearalenone mycotoxicoses
}

\author{
Monica Sabater-Vilar ${ }^{1}$, Hassan Malekinejad ${ }^{2}$, M.H.J. Selman ${ }^{1}$, M.A.M. van der \\ Doelen $^{1}$ \& Johanna Fink-Gremmels ${ }^{1}$ \\ ${ }^{1}$ Department of Veterinary, Pharmacology, Pharmacy and Toxicology, Faculty of Veterinary Medicine, \\ Utrecht University, Yalelaan 104, 3508 TD Utrecht, The Netherlands; ${ }^{2}$ Department of Pharmacology and \\ Toxicology, Faculty of Veterinary Medicine, Urmia University, Iran
}

Received 1 February 2006; accepted in revised form 9 January 2007

\begin{abstract}
The high prevalence of the Fusarium mycotoxins, deoxynivalenol (DON) and zearalenone (ZON) in animal feeds in mild climatic zones of Europe and North America results in considerable economic losses, as these toxins affect health and productivity particularly of pigs from all age groups. The use of mycotoxin adsorbents as feed additives is one of the most prominent approaches to reduce the risk for mycotoxicoses in farm animals, and to minimise carry-over of mycotoxins from contaminated feeds into foods of animal origin. Successful aflatoxin adsorption by means of different substances (phyllosilicate minerals, zeolites, activated charcoal, synthetic resins or yeast cell-wall-derived products) has been demonstrated in vivo and in vitro. However, attempts to adsorb DON and ZON have been less encouraging. Here we describe the adsorption capacity of a variety of potential binders, including compounds that have not been evaluated before, such as humic acids. All compounds were tested at realistic inclusion levels for their capacity to bind $\mathrm{ZON}$ and $\mathrm{DON}$, using an in vitro method that resembles the different $\mathrm{pH}$ conditions in the gastro-intestinal tract of pigs. Mycotoxin adsorption was assessed by chemical methods and distinct bioassays, using specific markers of toxicity as endpoints of toxicity in cytological assays. Whereas none of the tested substances was able to bind DON in an appreciable percentage, some of the selected smectite clays, humic substances and yeast-wall derived products efficiently adsorbed ZON (>70\%). Binding efficiency was indirectly confirmed by the reduction of toxicity in the in vitro bioassays. In conclusion, the presented test protocol allows the rapid screening of potential mycotoxin binders. Like other in vitro assays, the presented protocol combining chemical and biological assays cannot completely simulate the conditions of the gastro-intestinal tract, and hence in vivo experiments remain mandatory to assess the efficacy of mycotoxin binders under practical conditions.
\end{abstract}

Key words: Bioassay, deoxynivalenol, HPLC, mycotoxin adsorbent, zearalenone

\section{Introduction}

The term mycotoxin refers to a large number of chemically diverse toxic secondary metabolites formed by fungi imperfecti growing on agricultural commodities. Contamination of cereals and grains and related products with mycotoxins causes foodand feed-borne intoxications (mycotoxicoses) in man and livestock. In animal husbandry, mycotoxicoses impair animal health, welfare and productivity causing important economic losses [1]. Moreover, accumulation of mycotoxins in animal tissues may result indirectly in exposure to humans consuming products of animal origin, as demonstrated for aflatoxin $\mathrm{B}_{1}$ and its metabolite aflatoxin $\mathrm{M}_{1}$ that is excreted with dairy milk [2]. 
Among the more than 300 mycotoxins described as yet, aflatoxin $B_{1}$ and the group of fumonisins are the toxins of major concern in tropical and sub-tropical regions. In contrast, in Europe and other parts of the Northern Hemisphere, preharvest contamination with mycotoxins product by various members of the genus Fusarium, including deoxynivalenol (DON) (mostly produced by $F$. graminearum and $F$. sporotrichoides) and zearalenone $(\mathrm{ZON})$ (produced by $F$. graminearum and $F$. culmorum among others), are of major concern particularly in pig production, as pigs are particularly sensitive to the adverse effects of these toxins [3]. DON leads to symptoms like vomiting, diarrhoea, lower weight gain and feed intake, and causes immunosuppression [4]. ZON exerts remarkable oestrogenic effects and impairs fertility and reproduction in pigs and other farm animals [5].

To combat animal mycotoxicoses, different physical and chemical methods have been recommended for the detoxification of mycotoxin-contaminated feedstuffs [6-9]. Among them, the use of mycotoxin adsorbents as feed additives is one of the most promising and widely used approaches to reduce the risk for mycotoxicoses in farm animals, and to minimise carry-over of mycotoxins from contaminated feeds into animal-derived products $[10,11]$. Successful adsorption of aflatoxins by different substances, including phyllosilicate minerals, zeolites, activated charcoal, synthetic resins or yeast cell-wall-derived products, has been demonstrated in vitro and in vivo [12-17]. The efficacy of the compounds to adsorb ZON and DON has been investigated as well, but the results were less encouraging. An efficient adsorption of ZON by certain zeolites, yeast-wall derived products and polymeric adsorbents has been demonstrated in vitro [12, 18-22]. In vivo experiments, in which the ZON contaminated feed was supplemented with a mineral clay product, showed an improved female reproductive performance in minks, but failed to reduce the signs hyperestrogenicity [23]. The inclusion of a commercial product containing esterified glucomannan did also not reverse the increase in the uterine weight of female minks exposed to ZON [24], whereas fibre addition to the diet of rats appeared to decrease the toxicity of ZON [25]. A quaternary ammonium anion exchange resin, cholestyramine, has been shown to reduce $\mathrm{ZON}$ toxicity in the pre-pubertal mouse uterine weight bioassay [26]. Regarding DON, only in vitro adsorption by activated charcoal [27, 28] and to a lesser extend by yeast-derived products [29] has been reported. However, in feeding experiments with weaned piglets, Döll et al. (2005) [30] failed to demonstrate any beneficial effect of a modified aminosilicate product added to a diet that was naturally contaminated with Fusarium toxins, particularly with DON and ZON.

Since the polarity of the $\beta$-dicarbonyl group of aflatoxins is considered to play a pivotal role in their chemical adsorption to phyllosilicate clays (HSCAS) [31], it has been hypothesised that the lower polarity of ZON and DON is the reason for their lower binding affinity to these materials [32]. Subsequently, chemical modification of phyllosilicate clays with organic cations have been developed to improve $\mathrm{ZON}$ or DON adsorption. For example, Lemke et al. (1998) [33] developed an organophilic montmorillonite able to effectively bind $\mathrm{ZON}$ in vitro. However, when applied in vivo in the mouse uterine weight bioassay, an enhanced toxicity of ZON was observed, presumably due to the surfactant properties of desorbed quaternary ammonia which increased the rate of absorption of ZON [34]. These findings demonstrate that in the first screening of potential toxin binders, bioassays indicating a potential enhance absorption and toxicity should be included.

In consideration of these findings we developed a test protocol, which includes as a first step a conventional incubation procedure, indicating the binding capacity of new test compounds. As a second step we used specific bioassays, in which the aqueous phase of the incubation mixture was tested for toxin-specific effects in cell cultures.

In these combined assay, 20 different binders, including 6 commercial products, belonging to the following chemical classes were tested: smectites [35], humic substances [36, 37] and yeast cell-walls [38-40]. Activated charcoal served as reference compound, as it was shown to bind several mycototoxins, including aflatoxins, patulin, fumonisins, ochratoxin A, ZON and DON [10, 19-21]. The practical application of activated charcoal in feedstuffs, however, is restricted due to technical (dust formation and dark colour) and nutritional (adsorption of minerals, vitamins and other nutrients) limitations. The obtained findings were compared with those of commercial products 
containing various mineral clays, yeast products and plant extracts, as indicated.

\section{Materials and methods}

\section{Materials}

Three mineral clays (described in Table 1), six humic substances (described in Table 2), four yeast cell-wall derived products, six commercial 'mycotoxin binders' and activated charcoal were obtained from various companies in Europe, Asia and South America. The yeast cell wallderived products consisted of: natural yeast cellwall (Yeast1), modified yeast cell-wall (Yeast2), purified $\beta$-glucans (Yeast3) and purified mannoproteins (Yeast4). The composition of the commercial products as stated in the commercial brochures was as follows: Product 1: mixture of clay and yeast-cell wall; Product 2: yeast cellwall; Product 3: combination of yeast cell-wall, clay and plant extracts; Product 4: HSCAS (Hydrated Sodium Calcium Aluminum Silicate); Product 5: kaolinite, micaceous mineral, feldspar, quartz and carbonaceous material; and, Product 6: modified HSCAS.
Zearalenone (ZON), deoxynivalenol (DON) and MTT [(3-4,5-dimethylthiazol-2-yl)-2,5-diphenyltetrazolim bromide] were supplied by SIGMA (St. Louis, MO, U.S.A). Alamar blue (AB) was purchased from BioSource International (Camarillo, CA, USA). MCF-7 cells were obtained from (ECACC) European Collection of Cell Culture. Dulbecco's Modified Eagle's Medium (DMEM), phosphate buffered saline (PBS), foetal calf serum (FCS) and L-glutamine were purchased from Invitrogen (Breda, The Netherlands). All solvents used in chromatography were of HPLC grade; all other reagents were of analytical grade.

\section{Assessment of pH-dependent adsorption}

The tested products were suspended in PBS solution $\left(\mathrm{CaCl}_{2} \times 2 \mathrm{H}_{2} \mathrm{O}, 1.2 \mathrm{mM} ; \mathrm{KCl}, 2.7 \mathrm{mM} ; \mathrm{KH}_{2} \mathrm{PO}_{4}\right.$, $1.5 \mathrm{mM} ; \mathrm{MgCl}_{2} \times 6 \mathrm{H}_{2} \mathrm{O}, 1.1 \mathrm{mM} ; \mathrm{NaCl}, 138 \mathrm{mM}$; $\left.\mathrm{Na}_{2} \mathrm{HPO}_{4} \times 2 \mathrm{H}_{2} \mathrm{O}, 8.1 \mathrm{mM} ; \mathrm{pH}=6.5\right)$ to reach final concentrations of $5,2.5$ or $1 \mathrm{mg}$ of product/ ml. Either DON or ZON were added to this suspension at a final concentration of $1 \mathrm{mg} / 1$ (1 ppm). Two types of negative controls were included: (1) PBS solution with mycotoxin without adsorbent and (2) PBS solution with adsorbent without mycotoxin. The $\mathrm{pH}$ of the

Table 1. Composition of the natural mineral phyllosilicates investigated

\begin{tabular}{|c|c|c|c|c|c|c|c|c|c|c|c|c|c|}
\hline \multirow[t]{2}{*}{ Sample } & \multirow[t]{2}{*}{ Composition } & \multicolumn{8}{|c|}{ Physico-chemical properties ${ }^{\mathrm{a}}$} & \multicolumn{4}{|c|}{ Dry granulometry $(\%)$} \\
\hline & & $\begin{array}{l}\text { C.E.C. } \\
(\mathrm{meq} / 100 \mathrm{~g})\end{array}$ & $\begin{array}{l}\text { S.A. } \\
\left(\mathrm{m}^{2} / \mathrm{g}\right)\end{array}$ & $\begin{array}{l}\mathrm{CaCO}_{3} \\
(\%)\end{array}$ & $\begin{array}{l}\text { Moisture } \\
(\%)\end{array}$ & $\begin{array}{l}\% \text { Water } \\
\text { Absorption }\end{array}$ & $\mathrm{pH}$ & $\begin{array}{l}\text { Bulk } \\
\text { density } \\
(\mathrm{g} / \mathrm{l})\end{array}$ & $\begin{array}{l}\text { Ash } \\
(\%)\end{array}$ & $\begin{array}{l}>125 \\
\mu \mathrm{m}\end{array}$ & $\begin{array}{l}75 \\
\mu \mathrm{m}\end{array}$ & $\begin{array}{l}45 \\
\mu \mathrm{m}\end{array}$ & $\begin{array}{l}>45 \\
\mu \mathrm{m}\end{array}$ \\
\hline Minerall & $\begin{array}{l}\text { Smectite }(93 \%), \\
\text { Quartz }(5 \%), \\
\text { Dolomite }(1), \\
\text { Feldspar }(1 \%) \text { and } \\
\text { traces of plaster, } \\
\text { ilite and kaolinite }\end{array}$ & 45.4 & 60 & 4.0 & 7.74 & 77 & 7.4 & 820 & 9.23 & 4.8 & 12.9 & 18.9 & 63.5 \\
\hline Mineral2 & $\begin{array}{l}\text { Smectite }(95 \%), \\
\text { Quartz }(1 \%), \\
\text { Feldspar }(1 \%) \\
\text { and mica (traces) }\end{array}$ & 144.3 & 51 & 2 & 15.24 & 191 & 9 & 829 & 4.06 & 13.7 & 17.1 & 21.4 & 47.9 \\
\hline Mineral3 & $\begin{array}{l}\text { Smectite }(96 \%) \text {, } \\
\text { Quartz }(1 \%) \text { and } \\
\text { traces of plaster, } \\
\text { ilite and kaolinite }\end{array}$ & 41.4 & 114 & 2 & 7.18 & 121 & 8 & 844 & 7.09 & 4.5 & 16.8 & 23.6 & 55.2 \\
\hline
\end{tabular}

${ }^{\mathrm{a}}$ C.E.C. = Cation Exchange Capacity.

S.A. = Surface Area. 
mixtures were adjusted to 2.5 with $\mathrm{HCl}(1 \mathrm{M})$ and incubated at $37^{\circ} \mathrm{C}$ for $1 \mathrm{~h}$ under constant agitation to simulate the $\mathrm{pH}$ conditions during gastric passage in monogastric animal. After this first incubation step, a sample was taken for further analysis. The incubations were continued in the same flask by raising the $\mathrm{pH}$ of to $\mathrm{pH} 8.0$ with $\mathrm{NaOH}(1 \mathrm{M})$ and leaving the incubation mixture for $3 \mathrm{~h}$ under constant agitation at $37^{\circ} \mathrm{C}$ to simulate the $\mathrm{pH}$ conditions during intestinal passage of a monogastric animal. After this time, a second sample was taken. Both samples were immediately filtered (Minisart-GF with a retention efficiency of $98 \%$ for $0.7 \mu \mathrm{m}$ spherical particles; Sartorious, Gottingen, Germany) to separate the binder from the aqueous phase and stored at $-20^{\circ} \mathrm{C}$ until analysis.

\section{DON analysis by HPLC}

One millilitre $(1 \mathrm{ml})$ of each filtrated aliquot was cleaned-up using DON inmunoafinity columns (DONtest ${ }^{\text {TM }}$ HPLC; VICAM, Watertown, USA). The final methanol effluent was evaporated under a nitrogen stream and the obtained residue redissolved in $250 \mu \mathrm{l}$ of the mobile phase, of which $50 \mu$ were injected in the HPLC system. HPLC analyses were performed using a AS300 Thermo Separation Products HPLC system (SpectraPhysics, USA). A C18 ChromSpher, stainless steel, $5 \mu \mathrm{m}$ column $(100 \times 3.0 \mathrm{~mm}$, Chrompack, The Netherlands) was connected to SpectraSeries P100 Isocratic pumps set at a flow rate of $0.2 \mathrm{ml} / \mathrm{min}$. The mobile phase consisted of acetonitril : water (10:90 v:v). A UV150 detector set at $218 \mathrm{~nm}$ and linked to a Data Jet Integrator was used as detection system. The limit of quantification (LOQ) was estimated to be $0.05 \mathrm{mg}$ DON/1.

\section{ZON analysis by HPLC}

One and a half millilitres $(1.5 \mathrm{ml})$ of each filtrated aliquot were extracted with $7.5 \mathrm{ml}$ of chloroform. The water phase was discarded and the chloroform evaporated under a nitrogen stream. The obtained residue was re-dissolved in $200 \mu \mathrm{l}$ of mobile phase from which $50 \mu 1$ were injected in the HPLC system. A C18 Luna II, stainless steel, $5 \mu \mathrm{m}$ column $(150 \times 4.6 \mathrm{~mm}$; Phnomenex, The Netherlands) was connected to two high precision pumps (Gynkotek model 300) set at a flow rate of $0.7 \mathrm{ml} / \mathrm{min}$ and controlled by a Chromeleon-Gynkotec HPLC software (Softron). The mobile phase consisted of methanol / water (70:30 v:v). Fluorescence detection was performed with a FP 920 fluorescence detector (Jasco, Japan) set at $236 \mathrm{~nm}$ excitation wavelength and $418 \mathrm{~nm}$ emission wavelength. The limit of quantification was estimated to be $0.04 \mathrm{mg} \mathrm{ZON} / 1$.

\section{Bioassay for the evaluation of trichothecene cytotoxiciy}

Various authors have described that trichothecenes exert a typical cytotoxicity (42) and hence an established fibroblast cell line was used to measure the residual bioactivity of DON in the incubation samples. In brief, $5 \mathrm{ml}$ of each filtrated aliquot were lyophilised using a Freezemobile 6 unit (Virtis Company, USA). The residue was re-dissolved in $2 \mathrm{ml}$ of cell culture medium. This consisted of DMEM medium with phenol red supplemented with $10 \%$ bovine calf serum, $1 \%$ penicillin (100 units/ml), streptomycin $(100 \mu \mathrm{g} /$ $\mathrm{ml}), \quad 1 \%$ L-glutamine, $1 \%$ sodium pyruvate (1 mM). A monolayer culture of NIH/3T3LNCX, a cell line originating from mouse fibroblasts, was sub-cultured in DMEM medium and incubated at $37^{\circ} \mathrm{C}$ in a humidified atmosphere

Table 2. Composition of the natural humic substances investigated

\begin{tabular}{|c|c|c|c|c|c|c|c|c|c|}
\hline \multirow[t]{2}{*}{ Sample } & \multirow[t]{2}{*}{ Composition } & \multicolumn{4}{|c|}{ Physico-chemical properties } & \multicolumn{4}{|c|}{ Dry granulometry (\%) } \\
\hline & & Moisture (\%) & $\begin{array}{l}\% \text { Water } \\
\text { Absorption }\end{array}$ & $\mathrm{pH}$ & Bulk density (g/l) & $>125 \mu \mathrm{m}$ & $75 \mu \mathrm{m}$ & $45 \mu \mathrm{m}$ & $>45 \mu \mathrm{m}$ \\
\hline Humic1 & Leonardite & 18.5 & 56 & 3.9 & 663 & 9.3 & 19.5 & 26.1 & 45.1 \\
\hline Humic2 & Humic substances mixture & 14.6 & 44 & 7.1 & 661 & 52.6 & 16.5 & 12.6 & 18.4 \\
\hline Humic3 & Humic substances mixture & 54.9 & 82 & 9.4 & 568 & 26.9 & 9.8 & 18.6 & 44.7 \\
\hline Humic4 & Humic substances mixture & 2.0 & 55 & 7.8 & 799 & 8.1 & 9.0 & 19.9 & 63.0 \\
\hline Humic5 & Lignosulfonate & 7.4 & soluble & 8.2 & 434 & 5.4 & 12.5 & 48.2 & 33.9 \\
\hline Humic6 & Lignosulfonate & 8.0 & soluble & 6.2 & 481 & 6.6 & 41.5 & 28.5 & 23.4 \\
\hline
\end{tabular}


containing $5 \% \mathrm{CO}_{2}$ for 72 to $96 \mathrm{~h}$. After this time, the cells were detached and seeded into 96 well culture plates at a density of $10^{4}$ cells/well with $200 \mu \mathrm{lmedium} /$ well. After $24 \mathrm{~h}$ of incubation, the medium was removed and medium containing the lyophilised residue of the toxin-binder incubations and dilutions thereof were added. Incubation medium without DON was used as control. After $24 \mathrm{~h}$ of incubation, the Alamar Blue $(\mathrm{AB})$ reduction assay was performed as previously described [41]. Briefly, the medium was removed and fresh medium containing AB was added. Following $3 \mathrm{~h}$ of incubation, $\mathrm{AB}$ was measured fluorometrically at $530 \mathrm{~nm}$ (excitation) and $590 \mathrm{~nm}$ (emission). Data were expressed as relative absorbance in comparison to parallel incubations conducted with DON at the given concentration without any binding substance.

\section{E-screen bioassay assessing estrogenic activity}

This bioassay is based on the method of Soto et al. [42] and detects even small amounts of estrogenic activity associated with residual amounts of $\mathrm{ZON}$ and its metabolites. The assay was conducted with minor modifications as described previously [43]. Briefly, $5 \mathrm{ml}$ of each filtrated aliquot were lyophilised using a Freezemobile 6 unit (Virtis Company, USA). The residue was re-dissolved in $5 \mathrm{ml}$ of the cell culture medium. This consisted of DMEM medium without phenol red supplemented with $10 \%$ stripped bovine calf serum (estrogen-free), $1 \%$ penicillin (100 units $/ \mathrm{ml})$, streptomycin $(100 \mu \mathrm{g} / \mathrm{ml}), 1 \%$ L-glutamine, $1 \%$ sodium pyruvate $(100 \mathrm{mM})$, and $0.1 \%$ bovine insulin $(0.001 \mathrm{M})$. After sterilising by filtration $(0.25 \mu \mathrm{M}$; Corning, Germany), a $10^{6}$ dilution of the medium was prepared. A monolayer culture of human breast cancer cells (MCF-7) was sub-cultured in DMEM medium and incubated at $37^{\circ} \mathrm{C}$ in a humidified atmosphere containing $5 \% \mathrm{CO}_{2}$ for 72 to $96 \mathrm{~h}$. After this time, the cells were detached and seeded into 96 well culture plates at a density of $10^{4}$ cells/well with $200 \mu \mathrm{l}$ medium/well. After $24 \mathrm{~h}$ of incubation, the medium was removed and medium containing the lyophilised residue of the toxin binder incubations and dilutions thereof were added. Normal medium was used as control. After 6 days of incubation, the cell proliferation was assessed using the MTT (dimethylthiazol diphenyl tetrazolium bromide) test as described originally by Denizat and Lang (1986) [44], with minor modifications. Briefly, the medium was discarded and fresh medium containing $0.6 \mathrm{mg}$ $\mathrm{MTT} / \mathrm{ml}$ was added to the cells. After 3 to $4 \mathrm{~h}$ of incubation, the medium was removed and the reaction stopped by adding $\mathrm{HCl} /$ Iso-propanol 2:98 $(\mathrm{v} / \mathrm{v})$. Formazan, a product formed by the mitochondrial enzyme succinate dehydrogenase in viable cells, was measured at $590 \mathrm{~nm}$. Data were expressed as relative absorbance in comparison to control incubations conducted with ZON at the given concentrations without any binding substance.

\section{Calculation of the DON and ZON adsorption capacity per substance}

Two figures are given to express the DON and ZON adsorption capacity of each adsorbent. Figure 1, called acidic adsorption (Ac), is based on the analyses of the aliquots taken after the first incubation at low $\mathrm{pH}$. Figure 2, called alkaline adsorption (Ak), is based on the analyses of the aliquots taken after the second incubation conducted at alkaline $\mathrm{pH}$. Both, Ac and Ak, are calculated in percentage to the positive control (toxins without any adsorbent).

\section{Results}

In order to assess the mycotoxin binding capacity of the adsorbents, an in vitro system designed to mimic the temperature, $\mathrm{pH}$ and passage time through the stomach and the gut of a monogastric animal was applied. The DON and ZON adsorption after the acidic (Ac) and the alkaline (Ak) phases was assessed chemically (HPLC analysis) or biologically (cell assays) of the remaining, nonabsorbed mycotoxin in the filtered aliquot.

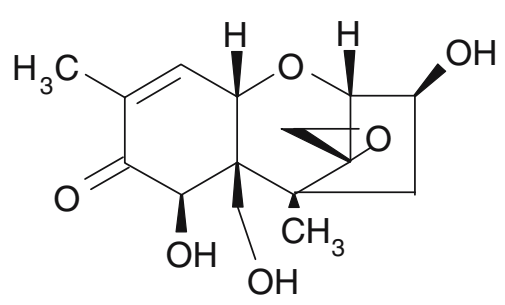

Figure 1. Structural formula of deoxynivalenol. 


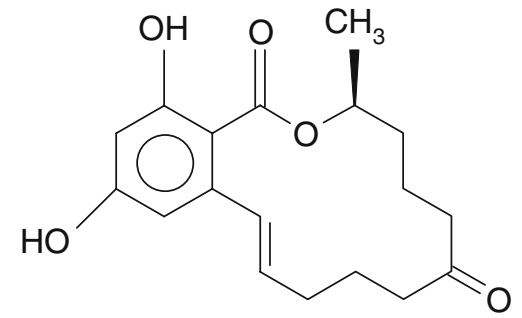

Figure 2. Structural formula of zearalenone.

\section{DON adsorption}

DON (1 ppm) adsorption was assessed by HPLC analysis of the unbound fraction in the filtrate of the incubation mixture. In addition, the same filtrate was applied in a standard cytotoxicity assay with NIH/3T3-LNCX cells. Aliquots from poor binders (high concentration of unbound DON) reduce the cell viability, whereas those from potent binders did not. DON adsorption (Ac and Ak) exhibited by the mineral clays, humic substances and yeast-derived products tested at a concentration of $5 \mathrm{mg} / \mathrm{ml}$ are presented in Table 3. The positive control, activated charcoal, was found to bind approximately $90 \%$ of DON in both assays. In contrast, all other products exerted a rather low DON adsorption, which was not significantly

Table 3. In vitro percentage adsorption of DON by different mineral clays, humic substances and yeast cell-wall derived products as assessed by chemical and biological methods*

\begin{tabular}{lccccc}
\hline Product $^{\mathrm{a}}$ & \multicolumn{2}{c}{ HPLC $^{\mathrm{b}}$} & & \multicolumn{2}{c}{ BIOASSAY $^{\mathrm{c}}$} \\
\cline { 2 - 3 } \cline { 5 - 6 } \cline { 5 - 6 } & Ac & Ak & & Ac & Ak \\
\hline Mineral1 & $8 \pm 7$ & $21 \pm 11$ & & $5 \pm 3$ & $11 \pm 8$ \\
Mineral2 & $9 \pm 8$ & $9 \pm 10$ & & $15 \pm 5$ & $10 \pm 3$ \\
Mineral3 & $5 \pm 6$ & $9 \pm 14$ & & $10 \pm 4$ & $15 \pm 11$ \\
Humic1 & $5 \pm 7$ & $9 \pm 11$ & & $9 \pm 7$ & $6 \pm 5$ \\
Humic2 & $5 \pm 10$ & $11 \pm 17$ & & $4 \pm 9$ & $18 \pm 7$ \\
Humic3 & $10 \pm 5$ & $10 \pm 17$ & & $3 \pm 8$ & $5 \pm 1$ \\
Humic4 & $8 \pm 4$ & $3 \pm 3$ & & $5 \pm 2$ & $4 \pm 3$ \\
Humic5 & $13 \pm 4$ & $21 \pm 1$ & & $9 \pm 9$ & $17 \pm 5$ \\
Humic6 & $10 \pm 3$ & 0 & & $11 \pm 10$ & $8 \pm 76$ \\
Yeast 1 & $1 \pm 1$ & $5 \pm 7$ & & $10 \pm 11$ & $10 \pm 6$ \\
Yeast 2 & $3 \pm 6$ & $12 \pm 13$ & & $8 \pm 7$ & $9 \pm 6$ \\
Yeast 3 & $8 \pm 5$ & $16 \pm 13$ & & $6 \pm 10$ & $15 \pm 7$ \\
Yeast 4 & $11 \pm 7$ & $15 \pm 19$ & & $13 \pm 9$ & $19 \pm 11$ \\
Charcoal & $88 \pm 7$ & $93 \pm 8$ & & $70 \pm 6$ & $80 \pm 10$ \\
\hline
\end{tabular}

*Values are means \pm SD of three independent experiments. $\mathrm{Ac}=$ acidic adsorption. $\mathrm{Ak}=$ alkaline adsorption.

aAll products were included at a concentrations of $5 \mathrm{mg} / \mathrm{ml}$;

${ }^{\mathrm{b}}$ Detection limit: $0.05 \mathrm{mg} / \mathrm{l}$; ${ }^{\mathrm{c}}$ Cytotoxicity Bioassay. different from control incubation without any binder, neither following HPLC analysis nor according to the results of the bioassay. This implies that most of the substances had an Ac and Ak lower than 10\%. Minerall and Humic5 achieved the highest Ak, which reached $21 \%$ (HPLC determination). The mineral and yeast products tended to exhibit higher Ak values as compared to the Ac values. These differences between Ac and Ak, however, were not significant $(p<0.050)$ as for all the other tested products. The adsorption capacity of these products decreased when tested at a higher toxin concentration of $2.5 \mathrm{mg} / \mathrm{ml}$ (data not shown). The individual DON adsorption values obtained for the commercial 'mycotoxin binders' tested at a concentration of $2.5 \mathrm{mg}$ binder per $\mathrm{ml}$, which resembles the recommended concentrations to be used in feeds, are presented in Table 4 . The obtained values were also very low $(<15 \%)$ for all the investigated products.

\section{ZON adsorption}

ZON adsorption was assessed by HPLC analysis of the unbound fraction in the incubation filtrates from 3 individual experiments with varying concentrations of the binder of $5 \mathrm{mg} / \mathrm{mg}, 2.5 \mathrm{mg} / \mathrm{ml}$ and $1 \mathrm{mg} / \mathrm{ml}$, respectively. The incubations conducted with $2.5 \mathrm{mg} / \mathrm{ml}$ adsorbent where in parallel assessed in a bioassay with MCF-7 cells, assessing the estrogenic activity of the unbound toxin fraction. Table 5 presents the results of ZON adsorption (Ac and Ak) exhibited by the smectites, humic acids and yeast cell wall materials. The reference material, activated charcoal, exhibited a near to $100 \%$ adsorption of $\mathrm{ZON}$ at all concentrations tested. The most effective compound (Ak and Ac $>70 \%$ at an inclusion rate of $2.5 \mathrm{mg} / \mathrm{ml}$ ) was Mineral1, followed by Humic1, Humic2, Humic4 and Yeast3. The other binding materials had Ac and $\mathrm{Ak}$ values that were considerably lower. For various products, notable differences were observed between individual Ac values and the corresponding AK values, for example for the compounds Mineral3, Humic3, Humic5 and Yeast3. These differences suggest the existence of an optimal concentrations of the binder and may serve a guidance for forthcoming in vivo studies Yeast4 showed a negligible adsorption rate when assessed by HPLC analysis but, surprisingly, 
Table 4. In vitro percentage adsorption of DON and ZON by different mineral clays, humic substances and yeast cell wall derived products as assessed by chemical and biological methods*

\begin{tabular}{|c|c|c|c|c|c|c|c|c|}
\hline \multirow[t]{3}{*}{ Product $^{\mathrm{a}}$} & \multicolumn{4}{|l|}{ DON } & \multicolumn{4}{|l|}{$\mathrm{ZON}$} \\
\hline & \multicolumn{2}{|l|}{ HPLC $^{\mathrm{b}}$} & \multicolumn{2}{|c|}{ Bioassay $^{c}$} & \multicolumn{2}{|l|}{ HPLC $^{\mathrm{d}}$} & \multicolumn{2}{|l|}{ Bioassay $^{\mathrm{e}}$} \\
\hline & Ac & $\mathrm{Ak}$ & Ac & $\mathrm{Ak}$ & Ac & $\mathrm{Ak}$ & $\mathrm{Ac}$ & $\mathrm{Ak}$ \\
\hline Product1 & $8 \pm 8$ & $9 \pm 6$ & $5 \pm 3$ & $4 \pm 8$ & $17 \pm 7$ & $35 \pm 7$ & $30 \pm 10$ & $40 \pm 12$ \\
\hline Product2 & $4 \pm 4$ & $5 \pm 10$ & $2 \pm 3$ & $3 \pm 3$ & $38 \pm 8$ & $32 \pm 8$ & $51 \pm 13$ & $24 \pm 16$ \\
\hline Product 3 & $7 \pm 10$ & $12 \pm 9$ & $5 \pm 3$ & $4 \pm 3$ & $40 \pm 8$ & $23 \pm 5$ & $60 \pm 14$ & $34 \pm 11$ \\
\hline Product4 & $11 \pm 15$ & $18 \pm 8$ & $6 \pm 5$ & $10 \pm 3$ & $25 \pm 5$ & $11 \pm 8$ & $39 \pm 12$ & $33 \pm 15$ \\
\hline Product5 & $13 \pm 15$ & $12 \pm 5$ & $10 \pm 5$ & $12 \pm 6$ & $2 \pm 4$ & $1 \pm 2$ & $36 \pm 13$ & $50 \pm 15$ \\
\hline Product6 & $7 \pm 8$ & $10 \pm 11$ & $11 \pm 6$ & $13 \pm 8$ & $97 \pm 0$ & $99 \pm 0$ & $98 \pm 2$ & $97 \pm 2$ \\
\hline Charcoal & $88 \pm 7$ & $93 \pm 8$ & $70 \pm 6$ & $80 \pm 10$ & $93 \pm 8$ & 100 & 100 & 100 \\
\hline
\end{tabular}

${ }^{*}$ Values are means $\pm \mathrm{SD}$ of three independent experiments. Ac = acidic adsorption. $\mathrm{Ak}=$ alkaline adsorption.

${ }^{\mathrm{a}}$ All products were included at a concentrations of $2.5 \mathrm{mg} / \mathrm{ml}$; ${ }^{\mathrm{b}}$ Detection limit: $0.05 \mathrm{mg} / \mathrm{l}$; ${ }^{\mathrm{c}}$ Cytotoxicity bioassay; ${ }^{\mathrm{d}}$ Detection limit: $0.04 \mathrm{mg} / 1 ;{ }^{\mathrm{e}}$ Cell Proliferation bioassay.

appeared to exert a quite considerably decrease in estrogenic activity $(\mathrm{Ac}=30 \%$ and $\mathrm{Ak}=69 \%)$ when tested in the bioassay. The results obtained with the commercial products are presented in Table 4. These products were tested only at an inclusion rate of $2.5 \mathrm{mg} / \mathrm{ml}$, which corresponds to the concentration recommended by the distributing commercial companies. The best product here was Product6 exhibited a binding activity of $>97 \%$ for Ac and Ak in both assays.

\section{Discussion}

Supplementing animal feeds with non-nutritive adsorbents has proven to substantially reduce the detrimental effects of $\mathrm{AFB}_{1}$ in farm animals [45] and the carry-over of $\mathrm{AFB}_{1}$ in milk [13]. Subsequently, various compounds have been tested for their potential to bind and sequester DON and $\mathrm{ZON}$. However, efficient binders of $\mathrm{AFB}_{1}$ often do not adsorb DON or ZON to any appreciable degree due

Table 5. In vitro percentage adsorption of $\mathrm{ZON}$ by different mineral clays, humic substances and yeast cell-wall derived products as assessed by chemical and biological methods*

\begin{tabular}{|c|c|c|c|c|c|c|c|c|}
\hline \multirow[t]{3}{*}{ Product $^{\mathrm{a}}$} & \multirow{2}{*}{\multicolumn{2}{|c|}{$\frac{5 \mathrm{mg} / \mathrm{ml}}{\mathrm{HPLC}^{\mathrm{b}}}$}} & \multicolumn{4}{|c|}{$2.5 \mathrm{mg} / \mathrm{ml}$} & \multirow{2}{*}{\multicolumn{2}{|c|}{$\frac{1 \mathrm{mg} / \mathrm{ml}}{\mathrm{HPLC}}$}} \\
\hline & & & \multicolumn{2}{|l|}{ HPLC } & \multicolumn{2}{|c|}{ BIOASSAY $^{\mathrm{c}}$} & & \\
\hline & Ac & Ak & Ac & $\mathrm{Ak}$ & Ac & Ak & Ac & Ak \\
\hline Minerall & $92 \pm 3$ & $88 \pm 6$ & $71 \pm 9$ & $74 \pm 2$ & $83 \pm 2$ & $74 \pm 3$ & $63 \pm 10$ & $43 \pm 1$ \\
\hline Mineral2 & $36 \pm 4$ & $6 \pm 11$ & $8 \pm 7$ & $4 \pm 7$ & $5 \pm 6$ & $1 \pm 2$ & $7 \pm 9$ & $2 \pm 2$ \\
\hline Mineral3 & $47 \pm 11$ & $15 \pm 11$ & $8 \pm 7$ & $4 \pm 7$ & $25 \pm 15$ & $7 \pm 14$ & $13 \pm 5$ & $5 \pm 4$ \\
\hline Humicl & $88 \pm 2$ & $67 \pm 3$ & $69 \pm 7$ & $68 \pm 10$ & $66 \pm 2$ & $56 \pm 5$ & $61 \pm 3$ & $57 \pm 9$ \\
\hline Humic2 & $90 \pm 1$ & $88 \pm 4$ & $69 \pm 13$ & $65 \pm 12$ & $78 \pm 15$ & $78 \pm 13$ & $68 \pm 2$ & $61 \pm 5$ \\
\hline Humic3 & $48 \pm 9$ & $16 \pm 5$ & $38 \pm 2$ & $13 \pm 11$ & $33 \pm 15$ & $21 \pm 17$ & $22 \pm 5$ & $17 \pm 1$ \\
\hline Humic4 & $98 \pm 8$ & $95 \pm 2$ & $94 \pm 3$ & $92 \pm 1$ & $87 \pm 10$ & $90 \pm 11$ & $56 \pm 11$ & $47 \pm 15$ \\
\hline Humic5 & $9 \pm 8$ & $38 \pm 15$ & $7 \pm 8$ & $15 \pm 1$ & $15 \pm 6$ & $17 \pm 6$ & $10 \pm 12$ & $17 \pm 3$ \\
\hline Humic6 & $9 \pm 8$ & $6 \pm 12$ & $2 \pm 4$ & $14 \pm 2$ & $11 \pm 8$ & $20 \pm 4$ & $4 \pm 4$ & $7 \pm 13$ \\
\hline Yeast 1 & $71 \pm 5$ & $68 \pm 6$ & $55 \pm 8$ & $48 \pm 1$ & $68 \pm 8$ & $52 \pm 12$ & $46 \pm 23$ & $30 \pm 5$ \\
\hline Yeast 2 & $67 \pm 1$ & $59 \pm 7$ & $50 \pm 7$ & $39 \pm 4$ & $58 \pm 13$ & $39 \pm 15$ & $39 \pm 11$ & $27 \pm 5$ \\
\hline Yeast 3 & $88 \pm 5$ & $77 \pm 1$ & $69 \pm 11$ & $55 \pm 4$ & $85 \pm 16$ & $72 \pm 11$ & $63 \pm 7$ & $33 \pm 9$ \\
\hline Yeast 4 & $3 \pm 4$ & $6 \pm 5$ & 0 & $2 \pm 3$ & $30 \pm 13$ & $69 \pm 17$ & 0 & $4 \pm 5$ \\
\hline Charcoal & 100 & 100 & $99 \pm 1$ & 100 & 100 & 100 & $97 \pm 1$ & $98 \pm 2$ \\
\hline
\end{tabular}

${ }^{*}$ Values are means \pm SD of three independent experiments. Ac $=$ acidic adsorption. Alkaline $=$ alkaline adsorption.

${ }^{\mathrm{a}}$ All products included at the three indicated concentrations: 5, 2.5 and $1 \mathrm{mg} / \mathrm{ml}$; ${ }^{\mathrm{b}}$ Detection limit: $0.04 \mathrm{mg} / \mathrm{l}$; ${ }^{\mathrm{c}}$ Cell Proliferation Bioassay. 
to the entirely different chemical structure of these Fusario-toxins. Therefore, various attempts have been made to identify new compounds, which efficiently bind DON and/or ZON. For the rapid screening of such new substance, a protocol for in vitro incubations at different $\mathrm{pH}$ level is presented, including chemical analysis of the unbound fraction, as well as cell-based bioassays. Comparable in vitro system consisted of a simple incubation series at different $\mathrm{pH}$ values according to the changes of the $\mathrm{pH}$ along the gastro-intestinal tract of pigs have been used before $[18,46]$ and were sometime completed by the addition of enzymes and bile fluid, to more closely resemble the conditions in the gastro-intestinal tract [22]. In these assays, the binding capacity of a given compound is usually measured by chemical analysis of the unbound toxin fraction that remains in the aqueous phase. We used a comparable experimental design for the incubations at different $\mathrm{pH}$ values as present in the gastrointestinal tract of pigs to assess the binding affinity at an acidic as well as an alkaline $\mathrm{pH}$, and added cellbased bioassays to the evaluation protocol. These biological assays are considered to be a valuable addition to the common chemical analysis of the unbound fraction, as they would detect unpredictable tenside-like activities of binders affecting the permeability of cell membranes and resulting in an increased cellular uptake and increase toxicity of the tested mycotoxins [33]. Given the differences in the mechanism of action of the two selected toxins, DON activity was tested in a cytotoxicity assay, whereas the biological activity of ZEN was tested in a proliferation assay with estrogen-dependent MCF-7 cells. Both assays have been used previously to compare the effects of trichothecenes (including DON) and estrogenic compounds (including ZEN) $[42,47]$.

The smectites, humic acids and yeast cell wall materials were added to the buffer system at concentrations of $1,2.5$ and $5 \mathrm{mg} / 1$, respectively, whereas the commercial binders were tested only at a concentration of $2.5 \mathrm{mg} / \mathrm{ml}$. These concentrations were chosen in consideration of the common practice, where inclusions rates exceeding $5 \mathrm{~kg}$ per metric ton of feed are avoided as they would impair the caloric and nutritional value of feeds, due to dilution and unspecific binding of essential feed ingredients such as trace minerals and vitamins. The toxin concentrations used in the assays were set at $1 \mathrm{mg} / 1$ (corresponding to $1 \mathrm{ppm}$ in feed) for DON and $\mathrm{ZON}$, respectively. This toxin level is very common for DON in mixed feeds, whereas exposure to ZEA is often lower. However, as ZEA can be present in bulk feeds such as corn silage as well as in concentrates, the same concentration was used in the described model experiments.

In this complex model new candidate binders, such as humic compounds, and previously used compounds were compared. According to our results, none of the tested products, except activated charcoal (which was included as positive control), appears to bind DON efficiently. In contrast, one mineral clay, three humic substances and one yeastderived product showed considerably high ZON adsorption, which makes the products candidates for further testing.

The results of the bioassay suggest a low toxicity of all binders tested, as no cytotoxicty was observed in the control incubations without the toxins. Moreover, the results of the bioassay exclude significant changes in the cellular uptake of the toxins, or possible mycotoxin-binder complexes. However, it should be mentioned that the latter possibility can not be entirely excluded, as only the overall reduction of the biological effects was measured, but not the actual intra-cellular concentration of the toxin. This would be only possible when radio-labelled toxins are used in the experiments. With one new compound, Yeast4, a considerable difference was found between the chemical and the biological assay. This product contains small-size purified manno-proteins, which may bind to ZON, but bypass the filtration. This would imply that the binding affinity of this product is underestimated in chemical analytical techniques that measure only the free, non-bound toxin fraction.

The comparison of all obtained results indicates that various compounds are effective in adsorbing ZEN, whereas none of the test compounds or commercial products was able to bind DON to an appreciable degree. These differences might be associated with typical characteristics in the chemical structures of the tested mycotoxins, as $\mathrm{ZON}$ exhibits a certain polarity in the $-\mathrm{O}-\mathrm{CO}-$ group, whereas DON lacks any comparable polar group. The presented results also show that within the tested classes of compounds such as smectite clays, humic substances and yeast-wall derived products, individual difference in the ability to adsorb ZON exist, demanding that only individual compounds and not classes of molecules can be tested, as long as 
the specific physico-chemical properties essential for the binding of $\mathrm{ZON}$ are elucidated.

An interesting finding is the good binding capacity of humic substances. As already mentioned in the introduction, polymeric humic substances contain various binding sites, and have been introduced into human medicine as compounds to reduce the absorption and systemic availability of bacterial endotoxins [48-50]. This latter effect would be highly beneficial in the protection of pig health as well, and hence these compounds deserve further in vivo testing.

A number of relevant factors occurring in vivo, such as interactions of toxins with feed components and the effect of digestive enzymes, which may cleave again the formed complexes between binders and toxins, are not reflected in the presented in vitro model. The obvious advantage of in vitro models, however, is the possibility to rapidly screen the effect of high numbers of different substances, enabling a pre-selection of products. Moreover, in vitro testing of the incubation media by means of bioassays will identify possible toxic reaction products (formed between binders and toxins) as well as significant toxic effects of the binders as such. In needs to be stressed, however, that any potential mycotoxin binders should be thoroughly assessed in in vivo experiments to demonstrate the capability in reducing mycotoxicosis in farm animals under field conditions.

\section{Acknowledgments}

The authors gratefully acknowledge SANLUC International NV (Melle, Belgium) for their financial support. They also would like to thank Roel Maas-Bakker for the stimulating discussions.

\section{References}

1. Mellor S. Mycotoxins in feed: a global challenge. Feed Mix 2001; 9: 26-28.

2. Trucksess MW, Richard JL, Stoloff L, MacDonald JS, Brumley WC. Adsorption and distribution patterns of aflatoxicol and aflatoxins $\mathrm{B}_{1}$ and $\mathrm{M}_{1}$ in blood and milk of cows given aflatoxin $\mathrm{B}_{1}$. Am J Vet Res 1983; 44: 1753-1756.

3. D'Mello JPF, Placinta CM, MacDonald AMC. Fusarium mycotoxins: A review of global implications for animal health, welfare and productivity. Anim Feed Sci Technol 1999; 80: 183-205.
4. Rotter BA, Prelusky DB. Toxicology of deoxynivalenol (vomitoxin). J Toxicol Environ Health 1996; 48: 1-34.

5. Gajecki M. Zearalenone - undesirable substances in feed. Pol J Vet Sci 2002; 5: 117-122.

6. Doyle MP, Applebaum RS, Brackett RE, Marth EH. Physical, chemical and biological degradation of mycotoxins in foods and agricultural commodities. J Food Prot 1982; 45: 946-971.

7. Piva GPF, Galvano FRD, Pietri AAP, Piva ARD. Detoxification methods of aflatoxins: A review. Nutr Res 1995; 15: 767-777.

8. Aziz NH, Attia ES, Farag SA. Effect of gamma-irradiation on the natural occurrence of Fusarium mycotoxins in wheat, flour and bread. Nahrung 1997; 41: 34-37.

9. Bata A, Lasztity R. Detoxification of mycotoxin-contaminated food and feed by microorganisms. Trends Food Sci Technol 1990; 10: 223-228.

10. Ramos AJ, Fink-Gremmels J, Hernandez E. Prevention of toxic effects of mycotoxins by means of non-nutritive adsorbent compounds. J Food Prot 1996; 59: 631-641.

11. Huwig A, Freimund S, Kappeli O, Dutler H. Mycotoxin detoxification of animals feed by different adsorbents. Toxicol Lett 2001; 122: 179-188.

12. Devegowda G, Aravind BIR, Morton MG. Saccharomyces cerevisiae and mannan-oligosacharides to counteract aflatoxins in broilers. Proc Aust Poult Sci Symp 1996; 8: 103-106.

13. Galvano F, Pietri A, Bertuzzi T, Fusconi G, Galvano M, Piva A, Piva G. Reduction of carry-over of aflatoxin from cow feed to milk by addition of activated carbons. J Food Prot 1996; 59: 551-554.

14. Kececi T, Oguz H, Kurtoglu V, Demet O. Efffects of polyvinylpolypyrrolidone, synthethic zeolite and bentonite on serum biochemical and haematological characters of broilers chickens during aflatoxicosis. Br Poult Sci 1998; 39: 452-458.

15. Miazzo RD, Rosa CAR, Carvalho ECQ, Magnoli C, Chiacchiera SM, Palacio G, Saenz M, Kikot A, Basaldella E, Dalcero M. Efficacy of synthetic zeolites to reduce the toxicity of aflatoxin in broiler chicks. Poult Sci 2000; 79: $1-6$.

16. Raju MVLN, Devegowda G. Influence of esterifiedglucomannan on performance and organ morphology, serum biochemistry and haematology in broilers exposed to individual and combined mycotoxicosis (aflatoxin, ochratoxin and T-2 toxin). Br Poult Sci 2000; 41: 640-650.

17. Rosa CAR, Miazzo R, Magnoli C, Salvano M, Chiacchiera SM, Ferrero S, Saenz M, Carvalho ECQ, Dalcero A. Evaluation of the efficacy of bentonite from the South of Argentina to ameliorate the toxic Effects of Aflatoxins in broilers. Poult Sci 2001; 80: 139-144.

18. Alegakis AK, Tsatsakis AM, Shtilman MI, Lysovenko DL, Vlachonikolis IG. Deactivation of mycotoxins. I. An in vitro study of zearalenone adsorption on new polymeric adsorbents. J Environ Sci Health 1999; B34: 633-644.

19. Galvano F, Piva A, Ritienei A, Galvano G. Dietary strategies to counteract the effects of mycotoxins: A review. J Food Prot 2001; 64: 120-131.

20. Avantaggiato G, Solfrizzo M, Visconti A. Recent advances on the use of adsorbent materials for detoxifi- 
cation of Fusarium mycotoxins. Food Addit Contam 2005; 22: 379-388.

21. Bueno DJ, di Marco L, Oliver G, Bardon A. In vitro binding of zearalenone to different adsorbents. J Food Prot 2005; 68: 613-615.

22. Avantaggiato G, Havenaar R, Visconti A. Assessing the zearalenone-binding activity of adsorbent materials during passage through a dynamic in vitro gastrointestinal model. Food Chem Tox 2003; 41: 1283-1290.

23. Bursian SJ, Aulerich RJ, Cameron JK, Ames NK, Steficek BA. Efficacy of hydrated sodium calcium aluminosilicate in reducing the toxicity of dietary zearalenone to mink. J Appl Toxicol 1992; 12: 85-90.

24. Bursian SJ, Mitchell RR, Yamini B, Fitzgerald SD, Murphy PA, Fernandez G, Rottinghaus GE, Moran L, Leefers K, Choi I. Efficacy of a commercial mycotoxin binder in alleviating effects of ochratoxin A, fumonisin B1, moniliformin and zearalenone in adult mink. Vet Human Toxicol 2004; 46: 122-129.

25. Stangroom KE, Smith TK. Whole and fractionated dietary alfalfa meal on zearalenone toxicosis and metabolsim in rats and swine. Can J Physiol Pharmacol 1984; 62: 1219-1224.

26. Underhill KI, Rotter BA, Thompson BK, Prelusky DB, Trenholm HL. Effectiveness of cholestyramine in the detoxification of zearalenone as determined in mice. Bull Environ Contam Toxicol 1995; 54: 128-134.

27. Galvano F, Pietri A, Bertuzzi T, Piva A, Chies I, Galvano M. Activated Carbons: In vitro affinity for ochratoxin A and deoxynivalenol and relation and relation of adsorption ability to physicochemical parameters. J Food Prot 1998; 61: 469-475.

28. Avantaggiato G, Havenaar R, Visconti A. Evaluation of the intestinal absorption of deoxynivalenol and nivalenol by an in vitro gastrointestinal model, and the binding efficacy of activated carbon and other adsorbent materials. Food Chem Tox 2004; 42: 817-824.

29. Devegowda G, Raju MVLN, Swamy HVLN. Mycotoxins: Novel solution for their counteraction. Feedstuffs 1998; 70: 12-15.

30. Döll S, Gericke S, Dänecke Raila S. J, Ueberschär K-H, Valenta H, Schnurrbusch U, Schweigert FJ, Flachowsky G. The efficacy of a modified aluminosilicate as a detoxicying agent in Fusarium toxin contaminated maize containing diets for piglets. J Appl Physiol Anim Nutr 2005; 89: 342-358.

31. Grant PG, Phillips TD. Isothermal adsorption of aflatoxin B1 on HSCAS clay. J Agri Food Chem 1998; 46: 599-605.

32. Huwig A, Freimund S, Kappeli O, Dutler H. Mycotoxin detoxication of animal feed by different adsorbents. Toxicol Lett 2001; 122(2): 179-188.

33. Lemke SL, Grant PG, Phillips TD. Adsorption of zearalenone by organophilic montmorrillonite clay. J Agri Food Chem 1998; 46: 3789-3796.

34. Lemke SL, Mayura K, Reeves WR. Investigation of organophilic montmorrillonite clay inclusion in zearalenone-contaminated diets using the mouse uterine weight bioassay. J Toxicol Environ Health 2001; 62: 243-258.

35. Barrer RM. Shape-selective sorbents based on clay-minerals - a review. Clays Clay Miner 1989; 37: 385-395.
36. Tate RL. Soil Organic Matter: Biological and Ecological Effects. Ed. New York: John Wiley \& Sons, INC, 1987.

37. Stevenson JF. Humus Chemistry: Genesis, Composition, Reactions. Ed. INC Illinois: John Wiley \& Sons, 1994.

38. Ballou CE. A study of the immunochemistry of three yeast mannans. J Biol Chem 1970; 245: 1197-1203.

39. Ofek I, Mirelman D, Sharon N. Adherence of Escherichia coli to human mucosal cells mediated by mannose receptors. Nature 1977; 265: 623-625.

40. Oyofo BA, Droleskey RE, Norman JO, Molenhauer HH, Ziprin RL, Corrier DE, DeLoach JR. Inhibition by mannose of in vitro colonization of chicken small intestine by Salmonella typhimurium. Poult Sci 1989; 68: 1351-1356.

41. Combes R, Manners J, Boavida P, Owen M, Clothier R. The effects of UVA on human corneal and keratinocyte cell lines. In: Clark D, Lissansky S, Macmillian R, eds. Alternatives to Animal Testing vol 2, CPL Press, Newbury UK, 1999: 152155.

42. Soto AM, Sonnenschein C, Chung KL, Fernandez MF, Olea N, Olea-Serrano MF. The E-SCREEN assay as a tool to identify estrogens: An update on estrogenic environmental pollutants. Environ Health Perspect 1995; 103: 113-122.

43. Malekinejad H, Maas-Bakker RF, Fink-Gremmels J. Bioactivation of zearalenone by porcine hepatic biotransformation. Vet Res 2005; 36: 799-810.

44. Denizat F, Lang R. Rapid colorimetric assay for cell growth and survival. J Immunol Meth 1986; 89: 271-277.

45. Ramos AJ, Hernandez E. Prevention of aflatoxicosis in farm animals by means of hydrated sodium calcium aluminosilicate addition to feedstuffs: A review. Anim Feed Sci Technol 1997; 65: 197-206.

46. Tomašević-Canović M, Daković A, Rottinghaus G, Matijašević S, Duričić M. Surfactant modified zeolites - new efficient adsorbents for mycotoxins. Micropor Mesopor Mat 2003; 61: 173-180.

47. Nasri T, Bosch RR, Voorde ST, Fink-Gremmels J. Differential induction of apoptosis by type A and B trichothecenes in Jurkat T-lymphocytes. Toxicol In Vitro 2006; 20: 832-840.

48. Janos P, Federociv J, Stankova P, Grotschelova S, Rijnek J, Stopka P. Iron humate as a low-cost sorbent for metal ions. Environm Technol 2006; 27: 169-181.

49. Ferrara G, Laffredo A, Seneci N, Morcos R. Humic acids reduce the genotoxicity of mitomycin $\mathrm{C}$ in the human lymphoblast cell like TK6. Mutat Res 2006; 603: 27-32.

50. Klavins M, Eglite L, Zicmanis A. Immobilized humic substances as sorbents. Chemosphere 2006; 62: 1500-1506.

51. Phillips TD, Sarr AB, Grant PG. Selective chemisorption and detoxification of aflatoxins by phyllosilicate clay. Nat Toxins 1995; 3: 204-213.

Address for correspondence: Monica Sabater-Vilar, Yalelaan 104, P.O. Box 80.152, 3508 TD Utrecht, The Netherlands

Phone: + 31-30-2535453; Fax: + 31-30-2534125

E-mail: monica_sabater@yahoo.es 